\title{
FEATURE Impact of the Agricultural Research Service Watershed Assessment Studies on the Conservation Effects Assessment Project Cropland National Assessment
}

\author{
Jeffery G. Arnold, R. Daren Harmel, Mari-Vaughn V. Johnson, Ronald Bingner, Timothy C. Strick- \\ land, Mark Walbridge, Chinnasamy Santhi, Mauro DiLuzio, and Xiuying Wang
}

\section{WATERSHED MODELING AND USDA CONSERVATION POLICY PLANNING}

The Soil and Water Resources Conservation Act (RCA) of 1977 provides the USDA broad strategic assessment and planning authority for the conservation, protection, and enhancement of soil, water, and related natural resources (USDA NRCS 2011). Through RCA, USDA

- appraises the status and trends of soil, water, and related resources on nonfederal land and assesses their capability to meet present and future demands;

- evaluates current programs, policies, and authorities; and

- develops a national soil and water conservation program to give direction to USDA soil and water conservation activities.

The 1985 RCA Appraisal was the first to use a comprehensive model (EPIC; Erosion Productivity Impact Calculator) to estimate the impact of soil erosion on crop productivity (Williams et al. 1984). EPIC is a field-scale model, and thousands of representative fields were modeled across the agricultural regions of the continental United States. The first watershed-based RCA assessment, called the Hydrologic Unit Model for the United States (HUMUS), was undertaken for the 1997 RCA Appraisal (Srinivasan et al. 1998; Arnold et al. 1999). HUMUS provides the necessary technical basis that enables the status of the nation's water resources to be determined at the national

Jeffrey G. Arnold is an agricultural engineer and R. Daren Harmel is a supervisory agricultural engineer at the Grassland Soil and Water Research Laboratory, USDA Agricultural Research Service (ARS), Temple, Texas. Mari-Vaughn V. Johnson is an agronomist for the USDA Natural Resources Conservation Service, Temple, Texas. Ronald Bingner is an agricultural engineer at the National Sedimentation Lab, USDA ARS, Oxford, Mississippi. Timothy C. Strickland is a supervisory research soil scientist at the Southeast Watershed Research Lab, USDA ARS, Tifton, Georgia. Mark Walbridge is national program leader for the USDA ARS, Beltsville, Maryland. Chinnasamy Santhi, Mauro DiLuzio, and Xiuying Wang are associate research scientists at the Blackland Research and Extension Center, Texas A\&M Agrilife Research, Temple, Texas. scale. The HUMUS framework enables modeling of spatially and temporally variable agricultural management across the United States, with outputs that quantify metrics related to water and soil quality.

The 2002 Farm Bill provided a significant increase in conservation program funding, which provided increased payments to land owners to implement conservation practices on their land. At the request of the Office of Management and Budget, USDA initiated the Conservation Effects Assessment Project (CEAP) in 2002 to analyze societal and environmental benefits gained from the increased conservation program funding. Building on lessons learned in the previous RCA projects, the CEAP Cropland National Assessment used the best concepts from both the 1985 and 1997 assessments. A detailed field and hill slope assessment was performed using the Agricultural Policy/ Environmental eXtender model (APEX; Williams and Izaurralde 2006), while the Soil and Water Assessment Tool (SWAT; Arnold et al. 1998, 2012) model was used to integrate the information at the watershed scale, using the US Geological Survey (USGS) developed eight-digit watersheds.

The Natural Resources Conservation Service (NRCS), Agricultural Research Service (ARS), and National Institute of Food and Agriculture (NIFA, formerly known as the Cooperative State Research, Education, and Extension Services) initiated the CEAP Watershed Assessment Studies (WAS) to estimate conservation benefits at the national and regional scales and to establish a scientific understanding of the impacts of conservation practices at the watershed scale (USDA NRCS 2010). Specifically, USDA initiated the WAS component of CEAP to (1) complement the Cropland National Assessment by providing more in-depth assessment of water quality and natural resource-related metrics associated with conservation practice impacts at a finer scale than is possible for the Cropland National Assessment, (2) provide a scientific framework for evaluating and improving the performance of the watershed assessment models, (3) allow for additional research on the impacts of different resource characteristics (such as climate, terrain, hydrology, and soils on conservation practice efficacy), and (4) further develop models to provide input to the national assessments (Mausbach and Dedrick 2004; Duriancik et al. 2008).

The CEAP watershed studies were divided into three groups, including the ARS benchmark watershed studies (figure 1), Cooperative State Research, Education, and Extension Service competitive grants watershed studies, and NRCS special emphasis watershed studies. The ARS benchmark watershed studies were conducted on 14 rain-fed, agricultural watersheds where long-term research on the impacts of conservation practices on soil and water could be assessed (Duriancik et al. 2008). Locations of all watersheds are shown in figure 2 .

The ARS benchmark watershed studies were structured into five specific objectives shown in table 1. To accomplish these objectives, ARS scientists were organized into six teams. A team was assigned to each of the five objectives listed in table 1 , with an additional team to conduct quality assurance across the CEAP WAS studies. The relationship of the six teams to the overall CEAP assessment is illustrated in figure 1.

Although this manuscript focuses on the impact of Objective 3, Modeling, the other teams were critical to the success of Objective 3 and to CEAP in general. To store and manage hydrologic, economic, management, and other data related to the watersheds, the Sustaining the Earth's Watersheds-Agricultural Research Database System (STEWARDS) was developed to fulfill the goals of Objective 1 (Steiner et al. 2009). STEWARDS is a web-based data system that integrates, stores, and manages data from the 14 benchmark watersheds for model input parameterization and ultimately model output (figure 2). Watershed design and monitoring (Objective 2) of these ARS benchmark watersheds supported the core of the science basis for CEAP and provided 
the data needed for the model validation and uncertainty component. Without the monitoring data and on-the-ground experiments that contributed to a better understanding of the conservation systems, further modeling analysis would not be possible. A special issue of the Journal of Soil and Water Conservation (Richardson et al. 2008) was devoted to monitoring and model applications at all 14 benchmark watersheds. Objective 4 integrates data from the watersheds and the model results into economic analysis for decision support (Whittaker et al. 2007; Confesor and Whittaker 2007). Objective 5, Regionalization of Models, captures legacy computer models into modular packages using collaborative object-oriented modeling system (David et al. 2013) methods to facilitate development of models applicable in specific regions of the United States. Work within this component provided an enhanced model structure and a framework for model development/maintenance and acts as a supporting tool for version control. Work within the quality assurance objective (Objective 6) led to standardization of methods and procedures across the WAS projects.

The focus of this manuscript is on the benefits derived by meeting Objective 3 on the Cropland National Assessment. The general approach to achieving Objective 3 was to validate output from the watershed models SWAT and Annualized Agricultural Nonpoint Source Pollution model (AnnAGNPS) (Bingner and Theurer 2001) using stream flow and water quality data collected from the benchmark watersheds. Within Objective 3 , six subobjectives were identified, and a description of each is given in table 2 .

While the intent of Objective 3 was to validate models and quantify uncertainties of model predictions, the application of the objective led to several enhancements of the models during the calibration and validation process, which will be described later. Additionally, improvements to the APEX and SWAT models outside of the WAS context have also benefitted the WAS objectives. Modeling improvements include (1) inclusion of the CENTURY carbon model, (2) improved denitrification routines, (3) development of

\section{Figure 1}

Relationship between the Conservation Effects Assessment Project national and watershed assessments, including the USDA Agricultural Research Service (ARS) benchmark watershed teams.

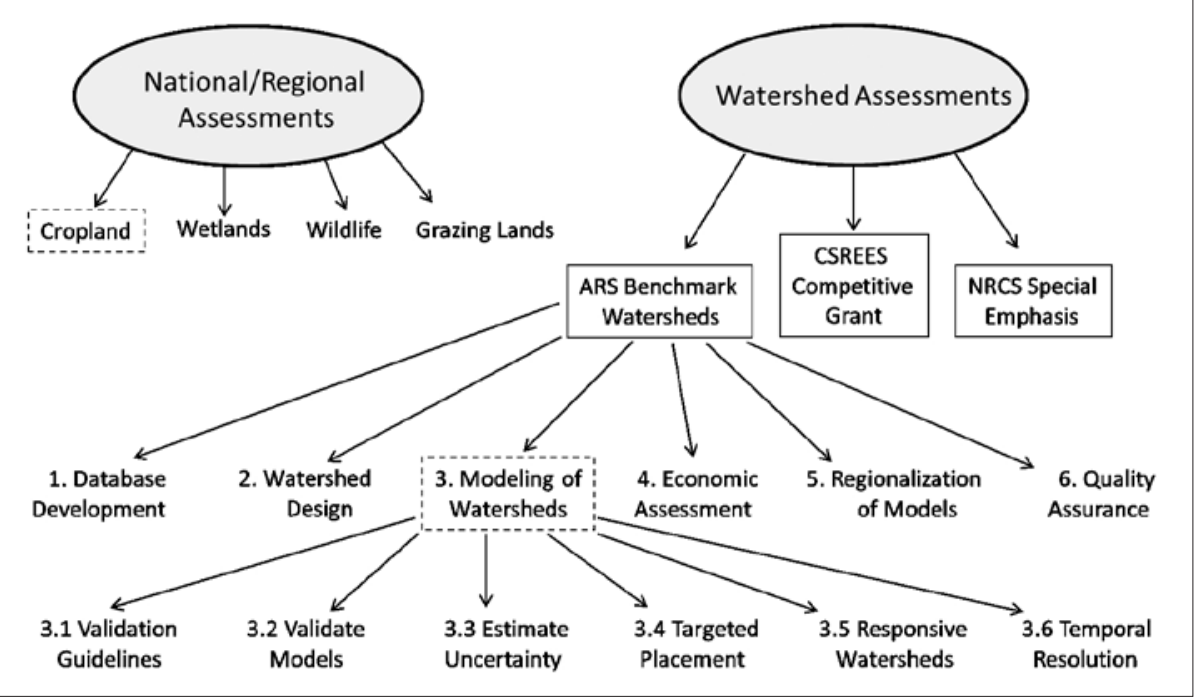

\section{Figure 2}

Location of Conservation Effects Assessment Project Watershed Assessment Study watersheds (Richardson et al. 2008).

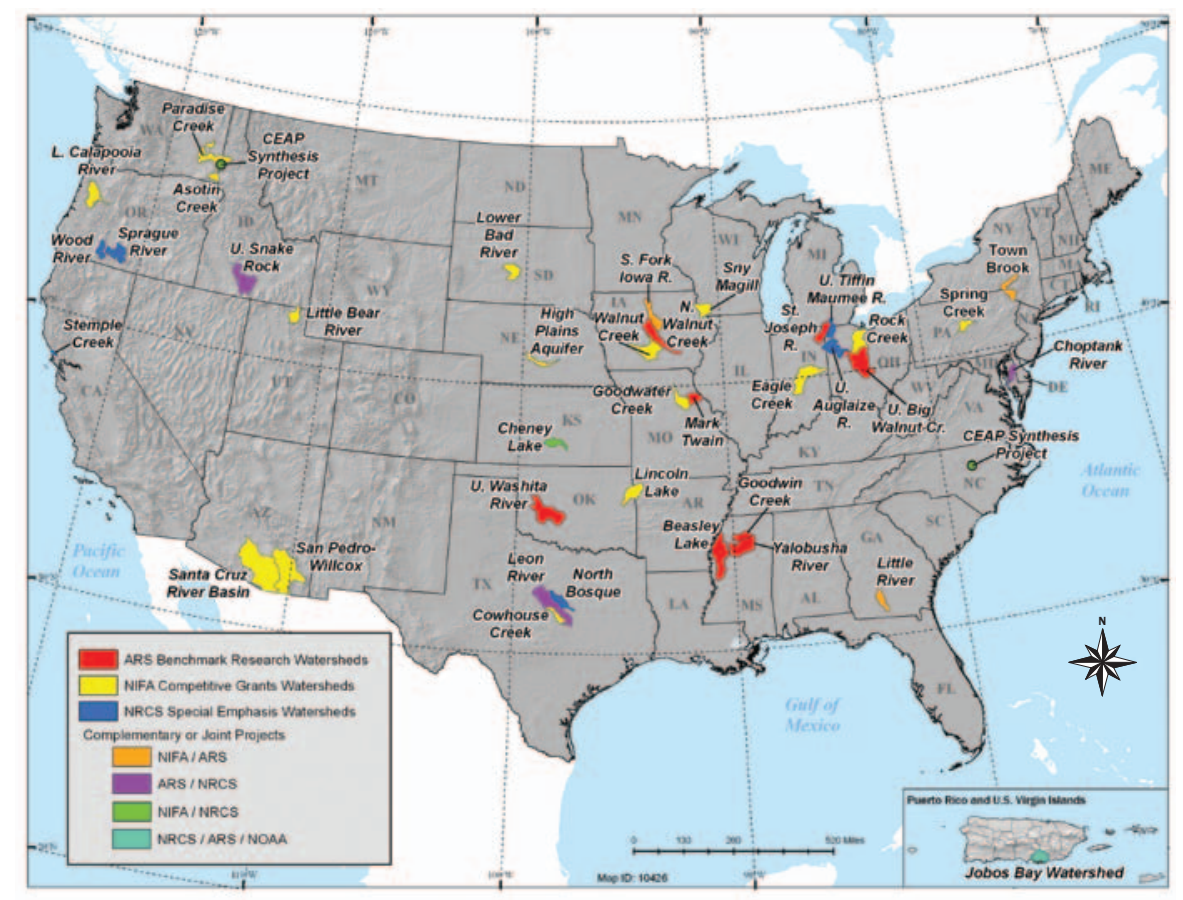

pathogen fate and transport algorithms, (4) capacity to represent preferential grazing, (5) improved flood routing, (6) inclusion of urban management practices, (7) linkages to groundwater and riparian models, and (8) development of tools for autocalibration and uncertainty analysis (Gassman et al. 2007; Tuppad et al. 2009; DouglasMankin et al. 2010; Santhi et al. 2014; Wang et al. 2011; Gassman et al. 2014). Additional areas of enhancements incorporated into AnnAGNPS include (1) ephemeral gully erosion, (2) riparian buffer components, (3) pollutant load source 


\section{Table 1}

Objectives of the USDA Agricultural Research Service (ARS)-Conservation Effects Assessment Project Watershed Assessment Study (USDA ARS 2014).

\begin{tabular}{|c|c|c|}
\hline Number & Objective & Description \\
\hline 1 & Database Development & $\begin{array}{l}\text { Develop and implement a web-based data system to organize, document, manipulate, and compile } \\
\text { climate, water, soil, land-management, and socioeconomic data from ARS research watersheds for } \\
\text { assessment of conservation practices and other hydrologic analyses. }\end{array}$ \\
\hline 2 & Watershed Design & $\begin{array}{l}\text { Measure and quantify water quality, water quantity, soil quality, and ecosystem effects of conservation } \\
\text { practices at the watershed scale in a variety of hydrologic and agronomic settings. }\end{array}$ \\
\hline 3 & Modeling of Watersheds & $\begin{array}{l}\text { Validate models and quantify uncertainties of model predictions at multiple scales by comparing } \\
\text { predictions of water quality to measured water, soil, and land management effects of conservation practices. }\end{array}$ \\
\hline 4 & Economic Assessment & $\begin{array}{l}\text { Develop and apply policy-planning tools to aid selection and placement of conservation practices to } \\
\text { optimize profits, environmental quality, and conservation practice efficiency. }\end{array}$ \\
\hline 5 & Regionalization of Models & $\begin{array}{l}\text { Develop and verify regional watershed models that quantify environmental outcomes of conservation } \\
\text { practices in major agricultural regions. }\end{array}$ \\
\hline 6 & Quality Assurance & Develop and implement a quality assurance system for all CEAP watershed assessments. \\
\hline
\end{tabular}

\section{Table 2}

Subobjectives of Agricultural Research Service (ARS) Watershed Assessment Studies (WAS) Objective 3, Modeling of Watersheds. (USDA ARS 2014).

\begin{tabular}{|c|c|c|}
\hline Number & Subobjective & Description \\
\hline 3.1 & Validation Guidelines & Develop model validation guidelines for systematic quantification of accuracy in WAS simulations. \\
\hline 3.2 & Validate Models & $\begin{array}{l}\text { Validate models using water quantity and water quality databases from the ARS benchmark watersheds and } \\
\text { make recommendations for further model enhancement and development and identify data gaps. }\end{array}$ \\
\hline 3.3 & Estimate Uncertainty & $\begin{array}{l}\text { Estimate uncertainty in model predictions resulting from calibration parameter identification and ranges of } \\
\text { input data resolution and quality. }\end{array}$ \\
\hline 3.4 & Targeted Placement & $\begin{array}{l}\text { Estimate the sensitivity of water quality responses to targeted placement of conservation practices and } \\
\text { suites of conservation practices within individual watersheds. }\end{array}$ \\
\hline 3.5 & Responsive Watersheds & $\begin{array}{l}\text { Develop tools to identify watersheds and/or sub-watersheds most likely to have the highest magnitude of } \\
\text { positive response to conservation practice implementation. }\end{array}$ \\
\hline 3.6 & Temporal Resolution & $\begin{array}{l}\text { Develop tools to estimate the temporal resolution (timing and magnitude) of conservation practice effects } \\
\text { within watersheds. }\end{array}$ \\
\hline
\end{tabular}

identification, and (4) controlled subsurface drainage (Yuan et al. 2006).

The objective of this manuscript is to outline the benefits of the ARS Watershed Assessment Studies effort on the CEAP Cropland National Assessment and specifically, to highlight the role of the ARS benchmark watersheds in advancing watershed modeling.

\section{IMPACTS OF OBJECTIVE 3: MODELING OF WATERSHEDS}

The modeling objective of the ARS WAS had several significant impacts on the CEAP Cropland National Assessment. Impacts of each of the six teams on ARS benchmark watersheds' Objective 3 are discussed below (see table 2 and figure 1).

Develop Model Validation Guidelines for Systematic Quantification of Accuracy in Watershed Assessment Study Simulations (Subobjective 3.1). At the start of the CEAP Cropland National Assessment (2003), specific criteria for accepting or rejecting models and model performance for the CEAP assessments were not established. In an attempt to develop the specific criteria, Moriasi et al. (2007) selected and recommended model evaluation techniques, reviewed published ranges of performance ratings for recommended statistics, and established guidelines for model evaluation based on project-specific considerations. A combination of graphical techniques and error statistics were proposed, including visual inspection of hydrographs and exceedance probability curves and a quantitative analysis of percent bias, root mean squared error, and Nash-Sutcliffe efficiency. Categorical performance ratings of very good, good, satisfactory, and unsatisfactory were developed based on error statistics and the time step of the analysis. Other factors con- sidered included quality and quantity of measured data, model calibration procedures, and project scope and magnitude. The model evaluation guidelines (Moriasi et al. 2007) were used in many of the CEAP model validation studies, including the Leon River in Texas (Rossi et al. 2008), the South Fork in Iowa (Green et al. 2006), and Beasley Lake Watershed in Mississippi (Yuan et al. 2008).

The beneficial outcomes from the ARS WAS effort have been more far-reaching than their original intent. The Moriasi et al. (2007) article has been cited over 650 times on Web of Science and over 1,120 times on Google Scholar (as of May 14, 2014) and has had significant impact in modeling studies well beyond the CEAP project. In fact, the evaluation of appropriate model evaluation techniques continues to impact the literature: as recently as 2012 , the American Society of Agricultural and 
Biological Engineers published a special collection of 22 research articles written by the model developers that discuss calibration and validation concepts used for 25 hydrologic and water quality models (Moriasi et al. 2012).

Validate Models Using Water Quantity and Water Quality Databases from the Benchmark Watersheds and Make Recommendations for Further Development (Subobjective 3.2). Provision of data against which the models could be validated is an essential function the ARS WAS served toward improving the CEAP Cropland National Assessment. The benchmark watershed validation gave increased confidence in the national cropland baseline calibration and in scenario simulations with commonly used conservation practices. All of the benchmark watersheds measured sediments, nitrogen $(\mathrm{N})$, and phosphorus (P). Pesticides were measured at 5 watersheds and pathogens at 3. Dissolved oxygen $\left(\mathrm{O}_{2}\right)$ and temperature were monitored at Beasley Lake, Mississippi, and Little River, Georgia. Major components of the water balance were also quantified, including precipitation (11 watersheds), discharge (11 watersheds), drainage (4 watersheds), soil water (5 watersheds), and groundwater (5 watersheds). Several soil, ecosystem, and economic characteristics were also measured. Conservation practices related to channel, drainage, manure, nutrient, and pesticide dynamics and management were evaluated in addition to application of buffers, tillage, application technologies, and land conversions (Tomer et al. 2014).

Validation of the models with data from ongoing research and published literature continues to provide lasting and cumulative benefits by iteratively improving modeling capacity to represent impacts of agricultural land management and conservation practice adoption in the CEAP Cropland National Assessment. Processes considered include subsurface drainage, fertilizer and manure management, buffers and grass waterways, riparian zones, and flood control structures. In addition to validation, many of the benchmark watersheds also contributed to model additions or enhancements. During validation, if simulation processes did not exist or were determined to be unacceptable, new routines were developed and incorporated into the models. This included routes for subsurface drainage, riparian zones, and buffers (White et al. 2009). In addition, tools for autocalibration and uncertainty analysis were developed and tested on the benchmark watersheds. References for validation and enhancements of each model can be found at the SWAT models websites: https://www. card.iastate.edu/swat_articles/INDEX. ASPX, http://apex.tamu.edu/publications/, and http://ars.usda.gov/Research/ docs.htm?docid= 5222 .

Estimate Uncertainty in Model Predictions Resulting from Calibration Parameter Identification and Ranges of Input Data Resolution and Quality (Subobjective 3.3). Much of the original development and push for quantification of uncertainty in APEX and SWAT simulations originated with the ARS CEAP Cropland National Assessment effort. Consideration of uncertainty is an essential component of using simulation models to inform conservation policy development because issues of uncertainty qualify model predictions. Numerous studies have quantified model response and uncertainty related to input data resolution, including Soil Survey Geographic database (1:12,000 to $1: 63,360$ scale) vs. State Soil Geographic database (1:250,000 scale) and resolution of land use and digital elevation models (DEMs) (Moriasi and Starks 2010; Starks and Moriasi 2009). As part of the CEAP effort, Veith et al. (2010) compared parameter sensitivity and uncertainty across a number of the ARS watersheds, representing a wide range of climatic, physiographic, and land use conditions. These watersheds included Mahantango, Pennsylvania $\left(7.2 \mathrm{~km}^{2}\right.$ [2.8 $\left.\mathrm{mi}^{2}\right]$ ), Little River, Georgia (330 km² [127 $\left.\left.\mathrm{mi}^{2}\right]\right)$, Little Washita, Oklahoma $\left(160 \mathrm{~km}^{2}\right.$ [62 $\left.\left.\mathrm{mi}^{2}\right]\right)$, Walnut Gulch, Arizona $\left(23.7 \mathrm{~km}^{2}\right.$ [9.2 $\left.\mathrm{mi}^{2}\right]$ ), and Reynolds Creek, Idaho (239 $\mathrm{km}^{2}$ [92 $\left.\left.\mathrm{mi}^{2}\right]\right)$. The shuffled complex evolution algorithm was employed in SWAT to calibrate each watershed. This process allowed for the construction of uncertainty bands around the simulated hydrographs, with the maximum widths of the uncertainty bands varying among watersheds based on regional condition, water size, and stream discharge rates. Veith et al. (2010) note that other types of uncertainty should also be considered, such as model process uncertainty, measurement frequency and techniques, and spatial and temporal fluctuations in climate.

This CEAP Cropland National Assessment focus on model uncertainty contributed to an increased interest in measurement uncertainty among APEX and SWAT modelers. As a result, ARS scientists initiated a targeted applied program to better understand uncertainty associated with measured hydrology and water quality data. The effort produced a set of practical guidelines to support water quality data collection in the CEAP context (Harmel et al. 2006) and an uncertainty estimation tool (Harmel et al. 2009), both of which are now listed in the USGS-Environmental Protection Agency National Environmental Methods Index (https://www.nemi.gov/)

In support of the ARS benchmark watersheds' Subobjective 3.3, methods continue to be developed to enhance consideration of measurement and model uncertainty in the evaluation of hydrologic and water quality models. Harmel and Smith (2007) proposed an evaluation method that includes the uncertainty in measured calibration/validation data in modified calculations of common model goodness-of-fit indicator values, such as the Nash Sutcliffe coefficient of efficiency (Nash and Sutcliffe 1970). The method of Harmel et al. (2010) further enhanced the model evaluation methodology by facilitating the inclusion of both measurement and model uncertainty in modified goodness-of-fit indicator calculations (Haan et al. 1995).

Estimate the Sensitivity of Water Quality Responses to Targeted Placement of Conservation Practices within Individual Watersheds (Subobjective 3.4). The 2014 Farm Bill proposes significant decreases in conservation payments to land owners compared to the 2002 Farm Bill. To maintain a high level of effective conservation with a lower budget, it would be advantageous for USDA to be able to identify and target the most appropriate conservation practice application to ensure the most cost-effective positive impact on water 
quality. Several studies within the ARS WAS project improved our ability to optimize both selection of and placement of management practices.

An optimization methodology was developed by Gitau et al. (2004) to determine the specific combination of management practices that optimized cost-effectiveness for a given farm or small watershed. The methodology combines SWAT for estimating watershed-specific loadings with a management tool that applies the current literature to estimate practice effectiveness in combination with management costs with genetic algorithm optimization to determine the most cost-effective scenario. The methodology was demonstrated for a 300 ha $(741 \mathrm{ac})$ farm in New York State by selecting and placing management practices to maximize $\mathrm{P}$ reduction while minimizing cost of practice adoption. Two scenarios met the established $60 \%$ dissolved $\mathrm{P}$ reduction target with cost increases of around US $\$ 1,500 \mathrm{y}^{-1}$ for the watershed. This methodology was refined and applied to the Town Brook Watershed $\left(37 \mathrm{~km}^{2}[14\right.$ $\left.\left.\mathrm{mi}^{2}\right]\right)$ as part of a watershed wide effort to reduce P losses to New York City water supply reservoirs (Gitau et al. 2008). Assuming the target resource conservation goal was a $60 \%$ reduction of soluble P, optimization favored adoption of comprehensive nutrient management plans, crop rotations, contour strip cropping, and riparian forest buffers. The most cost effective scenario achieved a cost effectiveness of US $\$ 24 \mathrm{~kg}^{-1}$ (US $\$ 10.9 \mathrm{lb}^{-1}$ ) of $\mathrm{P}$ removed per year compared to US $\$ 34$ $\mathrm{kg}^{-1}\left(\mathrm{US} \$ 15.4 \mathrm{lb}^{-1}\right)$ with the current basic implementation scheme.

These studies suggest it is cost effective to target selection and placement of management practices. This finding is useful for management decisions at multiple scales, from the field-scale land manager to the federal policy developer. These and other advances made recently in optimizing selection and placement of conservation practices continue to enhance the applicability of simulation models for land use decision making (Arabi et al. 2006; Secchi et al. 2007; Rabotyagov et al. 2010).

Develop Tools to Identify Watersheds and/or Subwatersheds Most Likely to Respond to Conservation Practice Implementation (Subbjective 3.5). Both SWAT and APEX predict responsiveness and loadings from fields and/or subwatersheds based on differences in soils, land use and management, topography, and climate. Because of the ability to simulate results at the field scale and the ability to parse watershed simulations into subwatershed analyses, APEX and SWAT are valuable tools toward providing information on which subwatersheds would provide the largest benefits of conservation practice implementation. This objective could inform the goal to better target conservation practices by providing a context for policy development.

Several tools have been developed to accommodate spatial input parameters and enhance display output including ArcSWAT (Olivera et al. 2006; Winchell et al. 2008) and ArcAPEX (Tuppad et al. 2009). Web-based tools have also been developed to visualize input and output and to enable spatially input management practices (Ahmadi et al. 2013). These tools assist in visualizing responsive watersheds and provide an initial first estimate of where spatially targeted management practices may be most effective.

Develop Tools to Estimate the Temporal Resolution (Timing and Magnitude) of Conservation Practice Effects within Watersheds (Subobjective 3.6). Analyses informing the CEAP Cropland National Assessment are typically based on results presented on an average annual basis. However, in order to capture the impacts of weather and management on conservation practice adoption efficacy, it is important for models to accurately simulate process and management impacts on a daily to seasonal basis. Most hydrology and plant growth processes in both SWAT and APEX are simulated on a daily time step. Runoff and flood routing process algorithms have recently been modified to operate on subdaily (e.g., hourly) time steps (Jeong et al. 2010, 2011); however, plant growth and nutrient/C cycling remain on a daily time step.

Impacts of timing and magnitude of conservation practice adoption were validated using data from the Walnut Creek Watershed in central Iowa. Water quality indicators were used to verify the capabil- ity of SWAT to predict the impact of a late spring nitrate $\left(\mathrm{NO}_{3}\right)$ soil test and rye (Secale cereale L.) cover crop management on $\mathrm{NO}_{3}$ reductions. The experiment led to enhancement to existing algorithms. Further, model output indicated a $25 \%$ reduction in $\mathrm{NO}_{3}$ under the late spring $\mathrm{NO}_{3}$ application compared to traditional early spring fertilizer timing (Saleh et al. 2007).

\section{IMPACTS OF MODEL VALIDATION ON THE CROPLAND NATIONAL ASSESSMENT}

The ARS WAS impact continues to inform the CEAP Cropland National Assessment and promises to have impacts on the other components of CEAP.

1. APEX and SWAT models were calibrated and validated at finer resolution than was previously possible using USGS stream gage data. During calibration and validation, several model shortcomings were discovered and consequently numerous improvements were made to both SWAT and APEX. The model enhancements allowed for calibration under known management conditions and also gave increased confidence in the models' abilities to scale up from the field to the eight-digit watersheds (the basic subwatersheds used in the CEAP Cropland National Assessment).

2. The work on model validation guidelines provided statistical goodness-of-fit recommendations for the CEAP Cropland National Assessment. In addition to the direct impact on CEAP simulations, the Moriasi et al. (2007) study has been cited in over 1,100 studies and is having impact well beyond CEAP.

3. Work on uncertainty created tools that are now being used more routinely in applying models for conservation and environmental assessment. CEAP also focused research on uncertainty in monitored data, thus increasing the awareness and appreciation of uncertainty in measured data, which are critical for water resource modeling and decision-making.

4. Tools were developed to aid in development of responsive watersheds and to estimate cost-effectiveness of spe- 
cific practices, suites of practices, and targeted placement.

5. Additional model development and validation was conducted to improve model response to timing of management and temporal resolution of process algorithms.

Arguably, the most important impact of ARS WAS studies on the CEAP Cropland National Assessment was the increased confidence in national simulations provided by the extensive model validation using data and knowledge gained from the ARS WAS studies.

\section{FUTURE DIRECTIONS}

Agricultural Research Service scientists and their collaborators continue research and watershed monitoring at several of the WAS benchmark watersheds. In addition, the 2013 budget for the ARS program initiative on Environmental Stewardship enabled ARS to establish 10 sites in its Long-term Agro-Ecosystem Research (LTAR) network (figure 3). While only a few of these Environmental Stewardship sites were also WAS benchmark watersheds (the Upper Mississippi River Basin Experimental Watersheds in Ames, Iowa; the Little Washita River in El Reno, Oklahoma; and the Little River Experimental Watershed in Tifton, Georgia), long-term agricultural experiments at these sites will continue to benefit both model development and the CEAP effort.

Research and development is also ongoing for modeling related to CEAP cropland, wildlife, wetlands, and grazing lands assessments. The CEAP Cropland National Assessment is being scaled down from 8 -digit to 12 -digit watersheds $(3,000$ to $100 \mathrm{~km}^{2}\left[1,158\right.$ to $\left.\left.39 \mathrm{mi}^{2}\right]\right)$ to allow more spatially accurate representation of climate and channel/reservoir routing. This exercise is contributing to improved modeling capacity for CEAP and other purposes.

The APEX and SWAT models are being recoded into a more modular structure to allow more efficient model development among teams of researchers and to improve maintainability of the models. In addition, algorithms for sediment transport, plant growth, nutrient cycling, and pathogen fate and transport are constantly being upgraded to meet the

\section{Figure 3}

Location of Conservation Effects Assessment Project Watershed Assessment Study watersheds (Richardson et al. 2008).

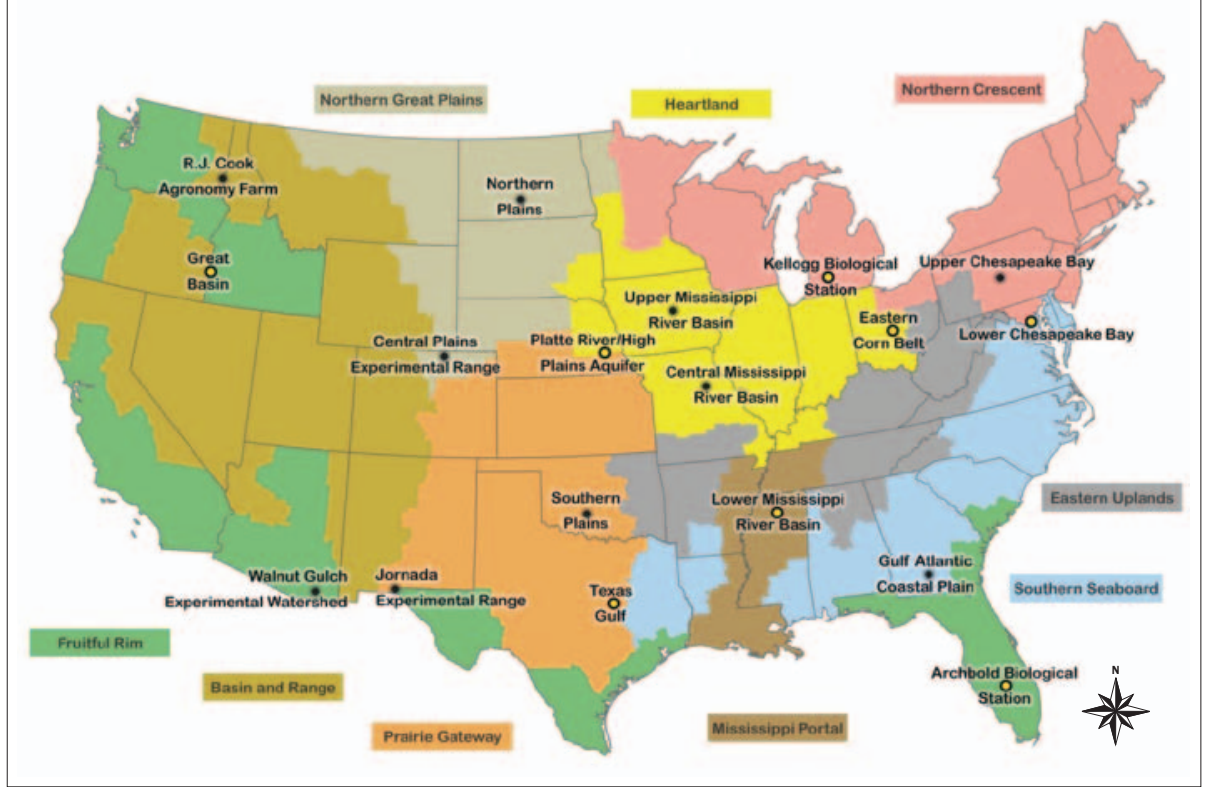

needs of CEAP and other conservation assessments across the globe.

\section{REFERENCES}

Ahmadi, M., M. Arabi, D.L. Hoag, and B.A. Engel. 2013. A mixed discrete continuous variable multiobjective genetic algorithm for targeted implementation of nonpoint source pollution control practices. Water Resources Research 49(12):8344-8356

Arabi, M., R.S. Govindaraju, and M.M. Hantush. 2006. Cost-effective allocation of watershed management practices using a genetic algorithm. Water Resources Research 42(10).

Arnold, J.G., D. Moriasi, P.W. Gassman, K.C. Abbaspour, M.J. White, R. Srinivasan, C. Santhi, R.D. Harmel, A. van Griensven, M.W.Van Liew, N. Kannan, and M. Jha. 2012. SWAT: model use, calibration, and validation. Transactions of the American Society of Agricultural and Biological Engineers 55(4):1491-1508.

Arnold, J.G., R. Srinivasan, R.S. Muttiah, and P.M. Allen. 1999. Continental scale simulation of the hydrologic balance. Journal of American Water Resources Association 35(5):1037-1051.

Arnold, J.G., R. Srinivasan, R.S. Muttiah, and J.R. Williams. 1998. Large area hydrologic modeling and assessment part I: Model development. Journal of American Water Resources Association 34(1):73-89.

Bingner, R.L., and F.D. Theurer. 2001. AnnAGNPS: Estimating sediment yield by particle size for sheet
\& rill erosion. In Proceedings of the Sedimentation: Monitoring, Modeling, and Managing, 7th Federal Interagency Sedimentation Conference, Reno, Nevada. p. I-1 - I-7.

Confesor, R.B., and G. Whittaker. 2007. Automatic calibration of hydrologic models with multiobjective evolutionary algorithm and Pareto optimization. Journal of the American Water Resources Association 43(4):981-989.

David, O., J.C.Ascough II, W. Lloyd, T.R. Green, K. W. Rojas, G.H. Leavesley, and L.R. Ahjua. 2013. A software engineering perspective on environmental modeling framework design: The object modeling system. Environmental Modelling \& Software 39:201-213.

Douglas-Mankin, K.R., R. Srinivasan, and J.G. Arnold. 2010. Soil and water assessment tool (SWAT) model: Current developments and applications. Transactions of the American Society of Agricultural and Biological Engineers 53(5):1423-1431.

Duriancik, L.F., D. Bucks, J.P. Dobrowolski, T. Drewes, S.D. Eckles, L. Jolley, R.L. Kellogg, D. Lund, J.R. Makuch, M.P. O’Neill, C.A. Rewa, M.R. Walbridge, R. Parry, and M.A. Weltz. 2008. The first five years of the Conservation Effects Assessment Project. Journal of Soil and Water Conservation 63(6):185A-197A, doi:10.2489/ jswc.63.6.185A.

Gassman, P.W., A.M. Sadeghi, and R. Srinivasan. 2014. Applications of the SWAT model spe- 
cial section: Overview and insights. Journal of Environmental Quality 43(1):1-8.

Gassman, P.W., M. Reyes, C.H. Green and J.G. Arnold. 2007. The soil and water assessment tool: Historical development, applications, and future research directions. Transactions of the American Society of Agricultural and Biological Engineers 50(4):1211-1250.

Gitau, M.W., T.L.Veith, W.J. Gburek, and A.R. Jarrett. 2008. Watershed level best management practice selection and placement in the Town Brook Watershed, New York. Journal of the American Water Resources Association 42(6):1565-1581.

Gitau, M.W., T.L.Veith, and W.J. Gburek. 2004. Farmlevel optimization of BMP placement for cost effective pollution reduction. Transactions of the American Society of Agricultural Engineers 47(6):1923-1931.

Green, C.H., M.D. Tomer, M. DiLuzio, and J.G. Arnold. 2006. Hydrologic evaluation of the soils and water assessment tool for a large tile-drained watershed in Iowa. Transactions of the American Society of Agricultural and Biological Engineers 49(2):413-422.

Haan, C.T., B. Allred, D.E. Storm, G.J. Sabbagh, and S. Prahhu. 1995. Statistical procedure for evaluating hydrologic/water quality models. Transactions of American Society of Agricultural Engineers 38(3):725-733.

Harmel, R.D., P.K. Smith, and K.L. Migliaccio. 2010. Modifying goodness-of-fit indicators to incorporate both measurement and model uncertainty in model calibration and validation. Transactions of the American Society of Agricultural and Biological Engineers 53(1):55-63.

Harmel, R.D., D.R. Smith, K.W. King, and R.M. Slade. 2009. Estimating storm discharge and water quality data uncertainty: A software tool for monitoring and modeling applications. Environmental Monitoring and Software 24(2009):832-842.

Harmel, R.D., and P.K. Smith. 2007. Consideration of measurement uncertainty in the evaluation of goodness-of-fit in hydrologic and water quality modeling. Journal of Hydrology 337(3-4):326-336.

Harmel, R.D., R.J. Cooper, R.M. Slade, R.L. Haney, and J.G. Arnold. 2006. Cumulative uncertainty in measured streamflow and water quality data for small watersheds. Transactions of the American Society of Agricultural and Biological Engineers 49(3):689-701.

Jeong, J., N. Kannan, J.G. Arnold, L. Gosselink, R. Glick, and R. Srinivasan. 2011. Development and integration of sub-hourly rainfall-runoff modeling capability in SWAT for urban watershed modeling. Water Resources Management 24:4505-4527.

Mausbach, M.J., and A.R. Dedrick. 2004. The length we go: Measuring environmental benefits of conservation practices. Journal of Soil and Water Conservation 59(5):96A-103A.

Moriasi, D.N., B.N. Wilson, K.R. Douglas-Mankin, J.G. Arnold, and P.H. Gowda. 2012. Hydrologic and water quality models: Use, calibration, and validation. Transactions of the American Society of Agricultural and Biological Engineers 55(4):1241-1247.

Moriasi, D.N., and P.J. Starks. 2010. Effects of the resolution of soil dataset and precipitation dataset on SWAT2005 streamflow calibration parameters and simulation accuracy. Journal of Soil and Water Conservation 65(2):163-178, doi:10.2489/jswc.65.2.63.

Moriasi, D.N., J.G. Arnold, M.W. Van Liew, R.L. Bingner, R.D. Harmel, and T.L. Veith. 2007. Model evaluation guidelines for systematic quantification of accuracy in watershed simulations. Transactions of the American Society of Agricultural and Biological Engineers 50(3):885-900.

Nash, J.E., and J.V. Sutcliffe. 1970. River flow forecasting through conceptual models, Part I: A discussion of principles. Journal of Hydrology 10(3):282-290.

Olivera, F., M. Valenzuela, R. Srinivasan, J. Choi, H. Chou, S. Koka, and A. Agrawal. 2006. ArcGISSWAT: A Geodata Model and GIS Interface for SWAT. Journal of the American Water Resources Association 42(2):295-309.

Rabotyagov, S., T. Campbell, M. Jha, P.W. Gassman, J. Arnold, L. Kurkalova, S. Secchi, H. Feng, and C.L. Kling. 2010. Least-cost control of agricultural nutrient contributions to the Gulf of Mexico hypoxic zone. Ecological Applications 20(6):1542-1555.

Richardson, C.W., D.A. Bucks, and E.J. Sadler. 2008. The Conservation Effects Assessment Project benchmark watersheds: Synthesis of preliminary findings. Journal Soil Water Conservation 63(6):590-604.

Rossi, C.G., T.J. Dybala, D.N. Moriasi, J.G. Arnold, C. Amonett, and T. Marek. 2008. Hydrologic calibration and validation of the soil and water assessment tool for the Leon River watershed. Journal of Soil and Water Conservation 63(6):453-460, doi:10.2489/jswc.63.6.533.

Saleh, A., E. Osei, D.B. Jaynes, B. Du, and J.G. Arnold. 2007. Economic and environmental impacts of LSNT and cover crops for nitratenitrogen reduction in Walnut Creek Watershed,
Iowa using FEM and Enhanced SWAT models. Transactions of American Society of Agricultural and Biological Engineers 50(4):1251-1259.

Santhi, C., N. Kannan, M. White, M. DiLuzio, J.G. Arnold, X. Wang and J.R. Williams. 2014. Integrated modeling approach for estimating the water quality benefits of conservation practices at river basin scale. Journal of Environmental Quality 43(1):177-198.

Secchi, S., P.W. Gassman, M. Jha, L. Kurkalova, H.H. Feng, T. Campbell, and C.L. Kling. 2007. The cost of cleaner water: Assessing agricultural pollution reduction at the watershed scale. Journal of Soil and Water Conservation 62(1):10-21.

Srinivasan, R., J. G. Arnold and C.A. Jones. 1998. Hydrologic modelling of the United States with the Soil and Water Assessment Tool. Water Resources Development 14(3): 315-325.

Starks, P.J. and D.N. Moriasi. 2009. Spatial resolution effect of precipitation data on SWAT calibration and performance: implications for CEAP. Transactions of the ASABE 52(4): 1171-1180.

Steiner, J. L. , E. J. Sadler, J. L. Hatfield, G. Wilson, D. James, B. Vandenberg, J. D. Ross, T. Oster and K. Cole. 2009. Data management to enhance long-term watershed research capacity: Context and STEWARDS case study. Ecohydology 2(4):391-398.

Tomer, M.D., E.J. Sadler, R.E. Lizotte, R.B. Bryant, T.L Potter, M.T. Moore, T.L. Veith, C. Baffaut, M.A. Locke, and M.R.Walbridge. 2014.A decade of conservation effects assessment research by USDA-ARS: Progress overview and future outlook. Journal of Soil and Water Conservation 69 (5):365-373.

Tuppad, P., M.F. Winchell, X. Wang, R. Srinivasan and J.R. Williams. 2009. ARCAPEX: ArcGIS interface for agricultural policy environmental extender (APEX) hydrology and water quality model. International Agricultural Engineering Journal 18(1-2): 59-71.

USDA ARS (Agricultural Research Service). 2014. CEAP Watershed Assessment Study. USDA Agricultural Research Service. http://www.ars. usda.gov/Research/docs.htm?docid= 18645 .

USDA NRCS (Natural Resources Conservation Service). 2010. Assessment of the Effects of Conservation Practices on Cultivated Cropland in the Upper Mississippi River Basin. US Department of Agriculture, Natural Resources Conservation Service.

USDA NRCS. 2011. RCA appraisal: Soil and Water Resources Conservation Act. July, 2011. http://www.nrcs.usda.gov/Internet/FSE_ DOCUMENTS/stelprdb1044939.pdf. 
Veith, T.L. M.W. Van Liew, D.D. Bosch, and J.G. Arnold. 2010. Parameter sensitivity and uncertainty in SWAT: A comparison across five USDA-ARS watersheds. Transactions of the American Society of Agricultural and Biological Engineers 53(5):1477-1485.

Wang, X., N. Kannan, C. Santhi, J.R. Williams, S.R. Potter, and J. G. Arnold. 2011. Integrating APEX output for cultivated cropland with SWAT simulation for regional modeling. Transactions of the American Society of Agricultural and Biological Engineers 54(4):1281-1298.

White, M.J., and J.G. Arnold 2009. Development of a simplistic vegetative filter strip model for sediment and nutrient retention at the field scale. Hydrological Processes 23:1602-1616.

Whittaker, G., R. Confessor, S.M. Griffith, R. Fare, S. Grosskopf, J.J. Steiner, G.W. Mueller-Warrant, and G.M. Banowetz. 2007. A hybrid genetic algorithm for multiobjective problems with activity analysis-based local search. European Journal of Operational Research 193(1):195-203.

Williams, J.R., C.A. Jones, and P.T. Dyke. 1984. A modeling approach to determining the relationship between erosion and soil productivity. Transactions of the American Society of Agricultural Engineers 27(1):129-144.

Williams, J.R., and R.C. Izaurralde. 2006. The APEX model. In Watershed Models, V.P. Singh and D.K. Frevert, eds, 437-482. Boca Raton, FL: CRC Press.

Winchell, M., R. Srinivasan, M. DiLuzio, and J.G. Arnold. 2008. Arc-SWAT 2.1 Interface for SWAT2005 - User's guide.Temple,TX: Blackland Research Center, Texas Agricultural Experiment Station and Grassland, Soil and Water Research Laboratory, USDA Agricultural Research Service.

Yuan, Y., M.A. Locke, and R.L. Bingner. 2008. Annualized agricultural non-point source model application for Mississippi Delta Beasley Lake watershed conservation practices assessment. Journal of Soil and Water Conservation 63(6):542-551, doi:10.2489/jswc.63.6.542.

Yuan, Y., R.L. Bingner, and F.D. Theurer. 2006. Subsurface flow component for AnnAGNPS. Applied Engineering in Agriculture 22(2):231-241. 